\title{
Androctonus genus species in arid regions: Ecological niche models, geographical distributions, and envenomation risk
}

\author{
Moulay Abdelmonaim El Hidan ${ }^{1}$, Oulaid Touloun ${ }^{1,2}$, Abdellah Bouazza ${ }^{3}$, Mehdi Ait Laaradia ${ }^{4}$ and Ali Boumezzough ${ }^{1}$
}

1. Department of Biology, Laboratory of Ecology and Environment, Faculty of Sciences Semlalia, Cadi Ayyad University, Marrakesh 40000, PO Box 2390, Morocco; 2. Department of Biology, Polyvalent Laboratory of Research \& Development LPVRD, Polydisciplinary Faculty, Sultan Moulay Slimane University, Beni Mellal, PO Box 23023, Morocco; 3. Faculty of Sciences, Biodiversity and Ecosystem Dynamics Laboratory, B.P. 2390, Cadi Ayyad University, Marrakech 40000, Morocco; 4. Department of Biology, Laboratory of Pharmacology, Neurobiology and Behavior, Faculty of Sciences Semlalia, University Cadi Ayyad, Marrakesh, Morocco.

Corresponding author: Moulay Abdelmonaim El Hidan, e-mail: elhidan@gmail.com

Co-authors: OT: o_touloun@yahoo.fr, AB: abdellah.bouazza@gmail.com, MAL: mehdi.aitlaaradia@gmail.com,

AB: aboumezzough@gmail.com

Received: 24-09-2017, Accepted: 02-02-2018, Published online: 06-03-2018

doi: 10.14202/vetworld.2018.286-292 How to cite this article: El Hidan MA, Touloun O, Bouazza A, Laaradia MA, Boumezzough A (2018) Androctonus genus species in arid regions: Ecological niche models, geographical distributions, and envenomation risk, Veterinary World, 11(3): 286-292.

\begin{abstract}
Aim: The objective of this study was to establish environmental factors related to scorpion species occurrence and their current potential geographic distributions in Morocco, to produce a current envenomation risk map and also to assess the human population at risk of envenomation.

Materials and Methods: In this study, 71 georeferenced points for all scorpion species and nine environmental indicators were used to generate species distribution models in Maxent (maximum entropy modeling of species geographic distributions) version $3.3 .3 \mathrm{k}$. The models were evaluated by the area under the curve (AUC), using the omission error and the binomial probability. With the data generated by Maxent, distribution and envenomation risk maps were produced using the "ESRI ${ }^{\circledR}$ ArcGIS 10.2.2 for Desktop" software.

Results: The models had high predictive success (AUC $>0.95 \pm 0.025$ ). Altitude, slope and five bioclimatic attributes were found to play a significant role in determining Androctonus scorpion species distribution. Ecological niche models (ENMs) showed high concordance with the known distribution of the species. Produced risk map identified broad risk areas for Androctonus scorpion envenomation, extending along Marrakech-Tensift-Al Haouz, Souss-Massa-Draa, and some areas of Doukkala-Abda and Oriental regions.
\end{abstract}

Conclusion: Considering these findings ENMs could be useful to afford important information on distributions of medically important scorpion species as well as producing scorpion envenomation risk maps.

Keywords: Androctonus genus, ecological niche models, Morocco, risk maps, scorpion envenomation.

\section{Introduction}

Scorpion envenomation is an important public health problem in many parts of the world; Central and South America, North Africa, the Middle East, and South Asia. Most venomous scorpions belong to the Buthidae family, which comprises species from the genera Androctonus and Buthus in North Africa, Tityus in South America, Centruroides in North and Central America, and Mesobuthus in Asia. The genus Androctonus is one of the largest and most widely distributed genera of the family Buthidae in North Africa. Species belonging to this genus are most frequently incriminated in severe scorpion stings. In fact, in the Maghreb area, scorpions of Androctonus genus are responsible for about 100,000 stings per year [1].

Copyright: El Hidan, et al. Open Access. This article is distributed under the terms of the Creative Commons Attribution 4.0 International License (http://creativecommons.org/licenses/ by/4.0/), which permits unrestricted use, distribution, and reproduction in any medium, provided you give appropriate credit to the original author(s) and the source, provide a link to the Creative Commons license, and indicate if changes were made. The Creative Commons Public Domain Dedication waiver (http:// creativecommons.org/publicdomain/zero/1.0/) applies to the data made available in this article, unless otherwise stated.
In Morocco, the genus Androctonus is represented by seven scorpion species [2].

Reporting of scorpion envenomation, by health authorities is generally deficient in most developing countries, as the majority of the patients first consulted traditional practitioners, which lead to a lack of information on scorpion stings and lethality incidence $[3,4]$. To evaluate accurate scorpion stings incidence and envenomation, it is important to count on community-based epidemiological studies independent of hospital reporting. However, this method would be expensive to apply at large scales [5]. Predictive models tools such as Geographic Information Systems (GIS) and ecological niche modeling (ENM) have been used to identify high envenomation risk regions related to other venomous animals (snakes and spiders) [6-8]. ENMs combined with GIS allow identifying high vulnerability regions to venomous animal and predicting species geographic responses to environmental variables as well. Whereas it takes into consideration the individual ecologies of those animals, and as a consequence, it gives unique opportunity to produce a risk map with the full complexity of the phenomenon. 
Therefore, we used ENM and GIS techniques to establish environmental factors related to species occurrence and current potential geographic distributions for species belonging to the Androctonus genus in Morocco, to produce a current envenomation risk map and also assessing the human population at risk of envenomation with species of this genus.

\section{Materials and Methods}

\section{Ethical approval}

This study was subject to the regulations of Public and Ethics Health committee in Morocco.

\section{Study area}

Morocco is located on the westernmost tip of North Africa with a surface of $720,000 \mathrm{~km}^{2}$. Characterized by its geography includes no $<4$ separate mountain ranges and wide expanses of desert. The three most prominent mountain ranges, which run parallel to each other from the southwest to the northeast, are the Middle Atlas, the High Atlas, and the Anti-Atlas. Moreover, the country is bordered by the North Atlantic Ocean to the west, and the west Mediterranean Sea to the north. In the south of the country, the Sahara is the largest desert in the world.

The climate in Morocco is as varied as its diverse geography. In general, the country has a Mediterranean climate. The coast has a warm, Mediterranean climate tempered on the eastern coast by southwest trade winds while inland areas have a hotter, drier, and continental climate. In the south of the country, the weather is very hot and dry throughout most of the year, though temperatures can drop dramatically at night, especially in the months of December-January.

\section{Study species}

Seven species' belong to Androctonus genus are present in Morocco: Androctonus amoreuxi, Androctonus australis, Androctonus gonneti, Androctonus liouvillei, Androctonus mauritanicus, Androctonus maroccanus, and Androctonus sergenti. However, we removed rare species since the meeting probability of these scorpions with humans is low, and because presence records for these species are scarce, which affects the performance of ENMs [6,9]. Thus, we had chosen as study species only species with six or more presence data in the country: A. amoreuxi, $A$. liouvillei, and A. mauritanicus.

\section{Scorpion sampling and identification and species range recording}

To locate scorpions, the ground was examined by lifting rocks, stones, and tree bark. The burrows considered to be occupied by scorpions were destroyed with a shovel to try to dislodge them. For the anthropophilic species, we investigated under stones and near indoor dwellings. The property that renders the scorpion carapace strongly fluorescent under ultraviolet light creates an excellent opportunity to detect these nocturnal arachnids. Hence, the nocturnal missions were conducted, using portable ultraviolet lamps. Specimens were identified in the laboratory using the keys and descriptions published by Vachon and Lourenço [2,10,11].

Distributional data representing 71 records (i.e., unique species $\times$ latitude-longitude combinations) for the three Androctonus species (A. amoreuxi - 22, A. liouvillei - 18, and A. mauritanicus - 31) were used to develop models, all of the records were unpublished observations by the authors. Observations were collected from the period between 2005 and 2015. For all observations, the geographic location was recorded with a Global Positioning System.

\section{Environmental data}

Environmental data used for species distribution models were represented by bioclimatic layers of current climatic trends [12]. To improve model precision and decrease problems with extrapolation, layers were clipped to the ecoregions that comprised occurrence records [13]. To avoid overfitting the models and improve model transferability, Pearson correlations between layers were calculated using ENMTool v. 1.3 [14]. When the Pearson's correlation coefficient was $>0.75$ [15] amid layers, one of the layers was chosen for models construction. These layers included in addition to the altitude and slope (derived from altitude raster with the "Slope" function of ArcGIS), seven climate grids (Table-1) [12].

\section{Ecological niche-based models}

Models were constructed with the maximum entropy approach [16]. This modeling technique requires only presence data as input, and consistently performed well in comparison to other methods [17], especially at low samples sizes $[9,18]$, scorpion records and environmental data were imported into MaxEnt v. 3.3.3 software [16]. A total of 20 model replicates were run with random seed. Thus, $20 \%$ of the presence points were used as test points and $80 \%$ for model training [19]. Records for each replicate were selected by bootstrap permitting sampling with replacement. Models were run with auto-features [16]. Model performance was assessed by the default evaluation of the area under the receiver operating characteristic curve (AUC) [20].

\section{Human population projections for risk assessment}

Human population data for the year 2015 were obtained from the Gridded Population of the World,

Table-1: Environmental factors used for model the distribution of Scorpion in Morocco and their codes and units.

\begin{tabular}{lll}
\hline Code & Variable & Unit \\
\hline ALT & Altitude & $\mathrm{M}$ \\
SLOP & Slope & $\%$ \\
Bio-2 & Mean diurnal range & ${ }^{\circ} \mathrm{C}$ \\
Bio-9 & Mean temperature of driest quarter & ${ }^{\circ} \mathrm{C}$ \\
Bio-16 & Precipitation of wettest quarter & $\mathrm{Mm}$ \\
Bio-18 & Precipitation of warmest quarter & $\mathrm{Mm}$ \\
Bio-19 & Precipitation of coldest quarter & $\mathrm{Mm}$ \\
\hline
\end{tabular}


Version 4 (GPWv4) [21]. The distribution layers had a resolution of $1 \mathrm{~km}$. These layers were overlaid with the models that predicted the presence of at least one scorpion species. The human population potentially exposed to scorpion envenomation was computed as that of those cells in which at least one scorpion species was present at the $10 \%$ levels.

\section{Envenomation risk maps}

To predict the probability of being envenomed by one of Androctonus scorpion species over the study area, we developed a risk map using the Maxent models of the three species. Performing risk map involves four steps:

- Map (1): Binary maps for each species were produced using the minimum presence value threshold value [6]. Before stacking and summing these layers, each species was weighted by its biological features linked to scorpion envenomation risk (see supplementary material).

- Map (2): Environmental suitability maps were developed from the seven components used in model calibration for all cells identified as suitable by the binary models. Briefly, maps of various environmental components were reclassified, and every class was weighted according to the probability of occurrence of each species. Then for each species, we overlaid and summed the seven environmental layers multiplying each by their weight which corresponds to their percent contribution. Finally, the three resulted layers were also overlaid and summed.

- Map (3): Most of the studies used population distribution and density to describe and model the risk of disease occurrence. It was presumed that scorpion envenomation incidence is related to the probability of encountering between human and scorpions and this probability is higher when the population density is high. Based on this assumption, map risk was computed using also a population density map derived from GPWv4 [21], this map was reclassified to 10 classes, and each class was weighted from 1 to 10 depending on the population density.

All the three resulted maps were stacked, summed, and normalized to lie between 0 and 1 which was interpreted as a relative measure of expected envenomation risk rate.

\section{Results}

ENMs produced in this study were better than random, as the ROC plots exhibited high average
AUCs with low standard deviations for both training and test datasets in all models (Table-2).

From the results of ecological models, we could distinguish ecological variables related to the distribution of each scorpion species. Thus, $A$. amoreuxi is mostly related to the mean temperature of driest quarter, mean diurnal range, and slope. While A. liouvillei is related to mean diurnal range, slope, precipitation of wettest quarter, and precipitation of warmest quarter. Finally, A. mauritanicus is related to precipitation of coldest quarter, altitude and precipitation of wettest quarter and precipitation of warmest quarter (Table-3).

The response of the three scorpion species toward each ecological factor is appraised based on response curves (Figure-1). All three species occur more frequently in areas with an altitude between 0 and $1500 \mathrm{~m}$ maximum density was observed at an approximate elevation of $700 \mathrm{~m}$ for $A$. liouvillei and A. amoreuxi, while for A. mauritanicus it was at $450 \mathrm{~m}$.

The three scorpion species respond differently to temperature variables (Figure-1), in fact, A. mauritanicus occur more frequently in areas with mean temperature of driest quarter between 6 and $25^{\circ} \mathrm{C}$ and between 6 and $19^{\circ} \mathrm{C}$ for mean diurnal range, while A. liouvillei is more likely present between 5 and $30^{\circ} \mathrm{C}$ for mean temperature of driest quarter and between 16 and $18^{\circ} \mathrm{C}$ for mean diurnal range. The probability of the presence of $A$. amoreuxi is elevated in areas when mean temperature of driest quarter and mean diurnal temperature are ranged between $25-35^{\circ} \mathrm{C}$ and $15-19^{\circ} \mathrm{C}$, respectively.

Precipitation is another factor that affects the distribution of three scorpion species. In general, all three species occur in regions with low precipitation of coldest quarter $(0-200 \mathrm{~mm})$. Regarding precipitation of warmest quarter, A. amoreuxi had a maximum probability of presence of 0.5 between 10 and $80 \mathrm{~mm}$, while $A$. mauritanicus occur mainly in areas with low precipitation of warmest quarter $(0-30 \mathrm{~mm})$ in contrast to A. liouvillei which is principally present in regions with high precipitation of warmest quarter $(60-90 \mathrm{~mm})$. For the last factor of precipitation, A. liouvillei and A. amoreuxi occur mainly in areas with low precipitation of wettest quarter with a maximum occurrence probability at 80 and $100 \mathrm{~mm}$, respectively (Figure-1).

Ecological models allowed identifying suitable habitats for the occurrence of the three scorpion species. Appropriate areas for A. amoreuxi were predicted mostly along parts of the Moroccan east from Mediterranean

Table-2: AUC and SD values obtained from internal and external model evaluation.

\begin{tabular}{lccr}
\hline Model performance & AUC for training data & AUC for test data & SD \\
\hline A. amoreuxi & 0.951 & 0.950 & 0.025 \\
A. liouvillei & 0.987 & 0.988 & 0.006 \\
A. mauritanicus & 0.975 & 0.969 & 0.007 \\
\hline
\end{tabular}

Note that for AUC the specificity is defined using predicted area, rather than true commission. This implies that the maximum achievable AUC is <1. A. amoreuxi: Androctonus amoreuxi, A. liouvillei: Androctonus liouvillei, A. mauritanicus: Androctonus mauritanicus, AUC=Area under the curve, SD=Standard deviation 
Table-3: Response values percent contribution and permutation importance (in \%) of the predictor variables for the ecological niche models of $A$. amoreuxi, A. liouvillei, and A. mauritanicus from Morocco.

\begin{tabular}{|c|c|c|c|c|c|c|}
\hline \multirow[t]{2}{*}{ Variables } & \multicolumn{3}{|c|}{ Percent contribution } & \multicolumn{3}{|c|}{ Permutation importance } \\
\hline & A. amoreuxi & A. liouvillei & A. mauritanicus & A. amoreuxi & A. liouvillei & A. mauritanicus \\
\hline Alt & 9.6 & 7.4 & 12.2 & 12.4 & 24.3 & 19 \\
\hline Slop & 20.7 & 18.6 & 4.6 & 20.7 & 37 & 2.5 \\
\hline $\mathrm{Bio} 2$ & 21.2 & 28.5 & 8.1 & 10.7 & 4.3 & 2.4 \\
\hline Bio9 & 28.1 & 6.4 & 0.5 & 2.3 & 0.2 & 0.9 \\
\hline Bio16 & 2.8 & 17.5 & 0.9 & 11.1 & 28.3 & 5.9 \\
\hline Bio18 & 4.4 & 17.1 & 10.1 & 4.3 & 5.4 & 3.6 \\
\hline Bio19 & 13.2 & 4.6 & 63.6 & 38.4 & 0.5 & 65.7 \\
\hline
\end{tabular}

A. amoreuxi=Androctonus amoreuxi, A. liouvillei=Androctonus liouvillei, A. mauritanicus=Androctonus mauritanicus

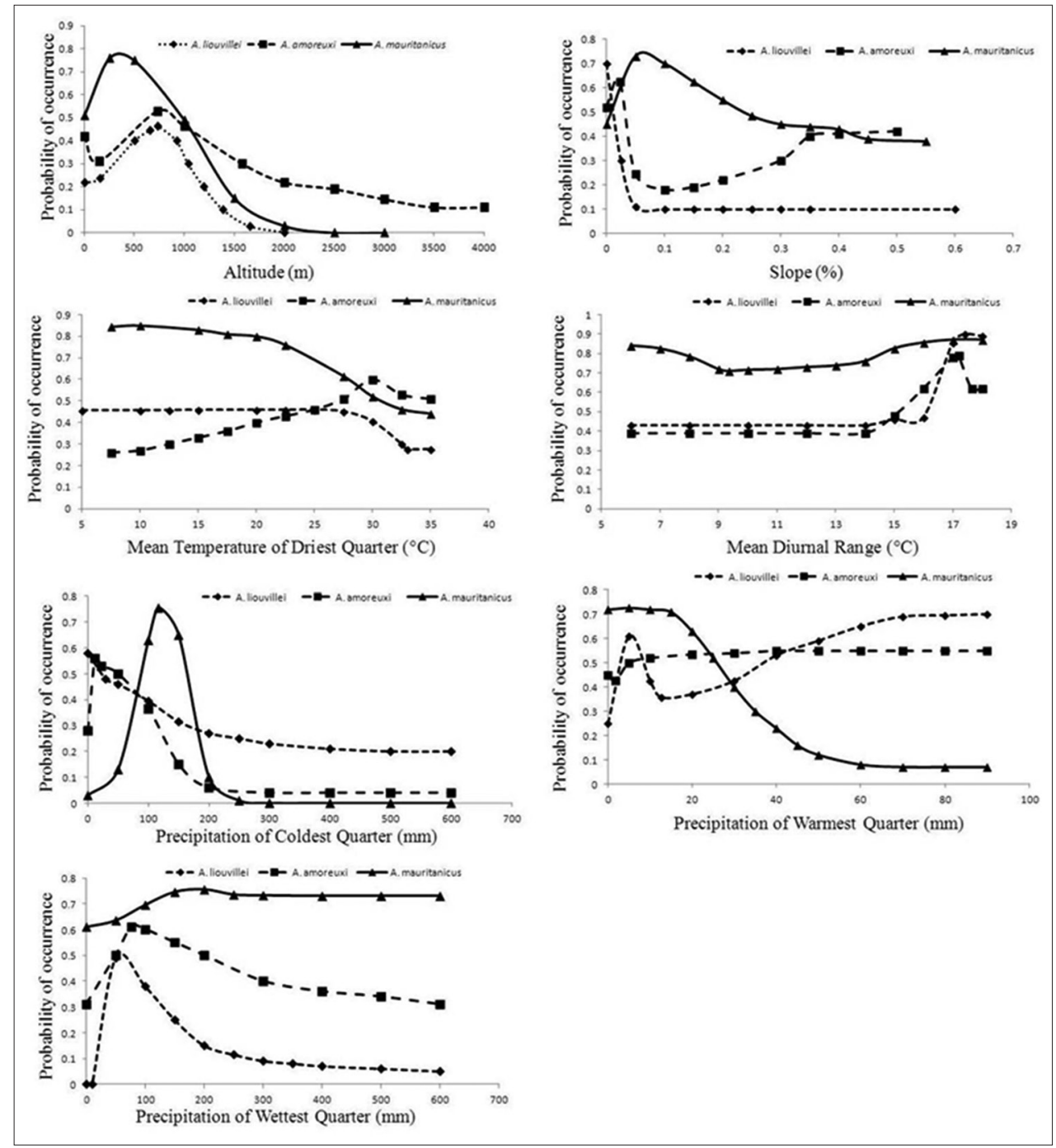

Figure-1: Response curves for the most related environmental factors to the distribution of Androctonus scorpion species in Morocco. Curves depict the average probability of occurrence from 20 model replicates along with the environmental gradients.

coast until Semara. Areas of high occurrence probability for A. liouvillei were located also in the east of the country as well as at some areas along the Atlantic coastline from Agadir to about Akhfennir. High presence probability for A. mauritanicus is located along Atlantic coastline between Eljadida and Tiznit as at some area in the northeast part of the study area (Figure-2).

Distribution area indicates a high occupied surface by $A$. amoreuxi flowed by $A$. liouvillei and
A. mauritanicus. However, the number of people at risk of envenomation by A. mauritanicus is higher than the two other species (Figure-3).

Scorpion envenomation risk map shows a wellspread risk through Morocco with "very high risk" regions located mainly in Marrakech-Tensift-Al Haouz (MTH), Souss-Massa-Draa (SMD), and some areas of Doukkala-Abda (DA), and Oriental regions. "High risk" also was situated in the same regions although 


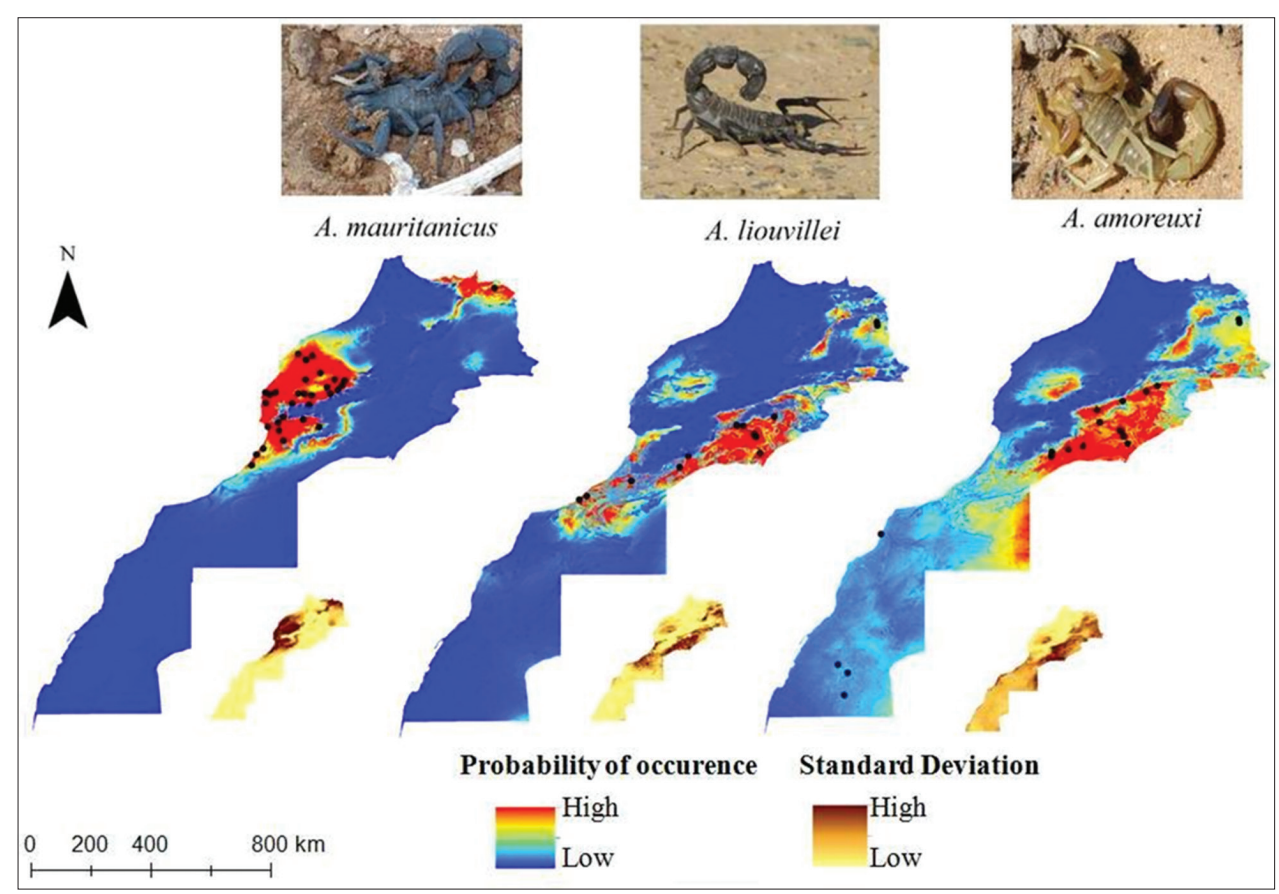

Figure-2: Average and standard deviation (small insets) of probability of occurrence of Androctonus scorpion species at a $1 * 1 \mathrm{~km}$ scale estimated from the ensemble of 20 model replicates.

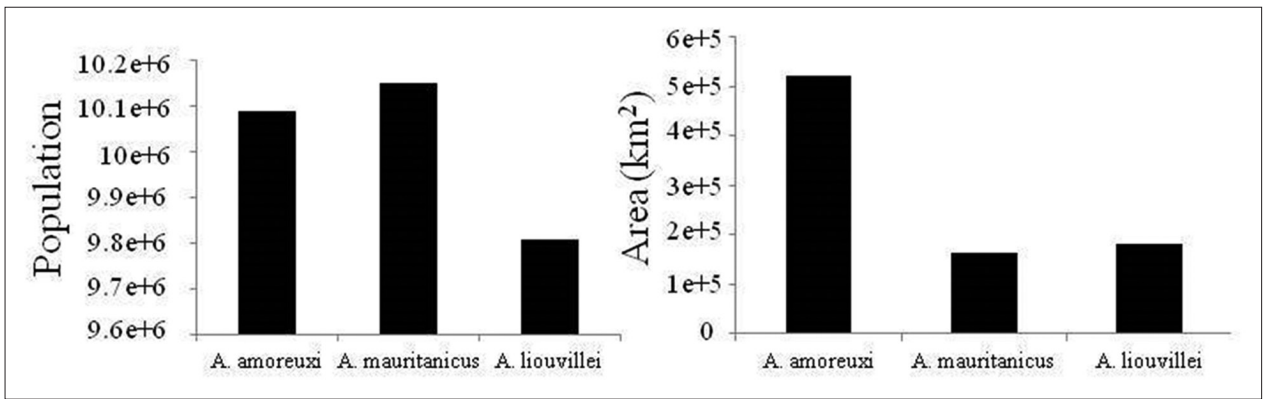

Figure-3: Histograms showing the area and human population under scorpion envenomation risk according to scorpion species.

limited parts in Tadla-Azilal (TA), Chaouia-Ouardigha (CO), Fes-Boulmane, Meknes-Tafilalet, and GuelmimEs-Semara also fell in this class. The other categories with "Medium, very low, and low envenomation risk" are principally in the North-West regions and southern regions of the country (Figure-4).

\section{Discussion}

ENM has been extensively used to predict the distribution of species related to diseases transmission [22].

The use of niche model tools could help for the characterization of medically important scorpion species distribution, and eventually predict the spatial risk of their suitable habitats. This may facilitate performing risk assessment maps and conception of specific control measures. GIS/ENM tools were successfully used in mapping envenomation risk for other venomous animals such as snakes and spiders [6-8,23]. The present study is the first attempt to use GIS/ENM to model current spatial distribution and scorpion envenomation risk in Morocco.
Environmental variables, such as topography and climate, can play important roles in envenomation extent by affecting the distribution and abundance of venomous animals. Indeed climate could affect scorpion distribution by two main components; rainfall (relative humidity) and temperature [24]. In fact, Warburg et al. had reported that rainfall has an obvious effect on scorpion distribution in Israel [25], while temperature constitutes the main factor limiting the southward expansion of tropical scorpion species on the east coast of Australia [26]. In this study, all environmental variables appear to contribute positively to the final predictive models. However, we found that each species was most strongly associated with specific environmental factors. Thus mean diurnal range, slope precipitation of wettest quarter, and warmest quarter were consistently related to the distribution of A. liouvillei. Whereas A. amoreuxi was more associated to the mean temperature of driest quarter, mean diurnal range, and slope while A. mauritanicus was mostly affected by precipitation of coldest and warmest quarter. 


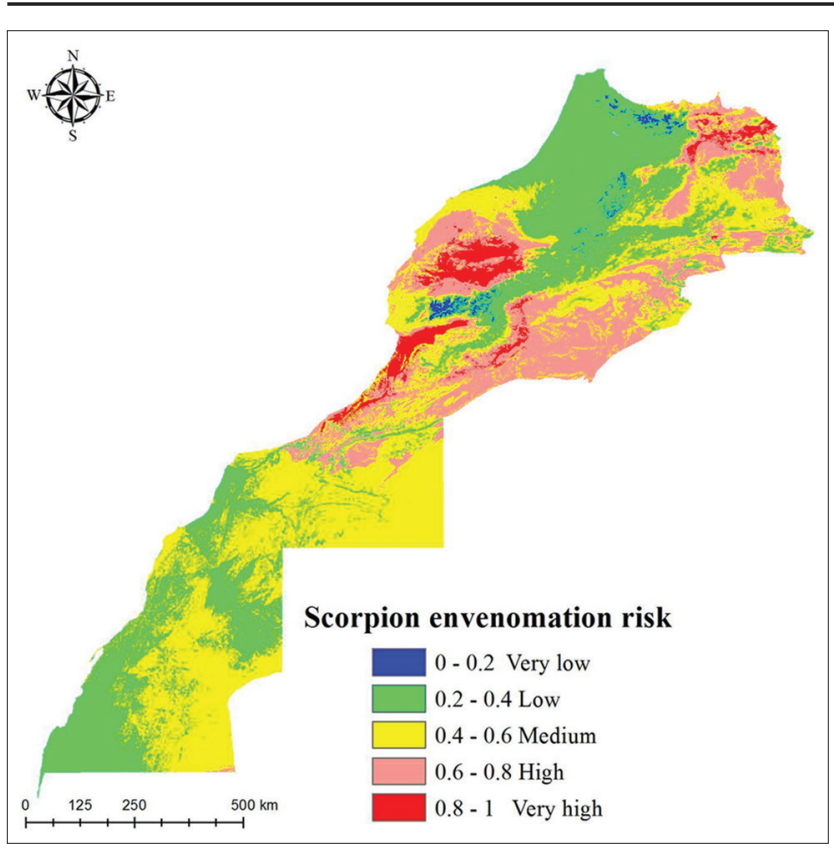

Figure-4: Androctonus scorpion envenomation risk predictions in Morocco.

Scorpion envenomation risk maps were based on ENMs produced for a medically important scorpion genus (Androctonus) in Morocco. Based on our evaluations, all niche models were well performed. We produced detailed current distributional maps for the three species most medically relevant and the most widespread in Morocco.

Our results reflect the known distribution of the three scorpion species fairly well. However, modeled distribution of $A$. amoreuxi and A. liouvillei predicts the occurrence of the two species in the region of Marrakech, even if the presence of these species had never been mentioned in. This incongruence either indicates model failure, with models including regions not ecologically suitable for the species, or the models are correct, and the two species are not found in Marrakech region due to the presence of barriers which limited dispersion potential. The latter scenario is more plausible with the presence of large geographical barrier represented in the Atlas Mountains which is known to limit the dispersion of arthropods especially scorpions [27].

Androctonus is possibly the most dangerous genus in North Africa, because of its wide distribution, size, and the high toxicity of its venom [28]; also species belonging to this genus is well adapted to anthropized habitats, making scorpion-human encounters frequent especially close to rural dwellings.

Current scorpion envenomation risk predictions show a high envenomation risk in MTH, SMD, and some parts of DA, those results corroborate previous data. In fact, Aboumaâd et al. [29] in his review on scorpion envenomation in Morocco had reported that the three regions with high envenomation incidence are orderly MTH, SMD, and CO. Furthermore, epidemiological study conducted in MTH and SMD had reported that scorpion envenomation is an important health problem in those two regions with a high incidence and lethality rate [30].

In spite of our focus on species belonging to the genus Androctonus as a principal cause of scorpion envenomation in Morocco, we note that the situation must be considerably more complex in reality. That is, considering the distribution of this species, it cannot account for the full envenomation incidence as regions of known "high envenomation incidence" such as CO and TA fall outside of the "high risk" area. This could be explained by the presence of other medically important species characterized by their highly toxic venom and wide distribution such as Hottentotta gentili and Buthus occitanus [31].

\section{Conclusion}

This study demonstrates the ability of GIS/ENMs to supply detailed information on potential distributions of a medically important scorpion, in addition to estimating and mapping scorpion envenomation risk. Finally, risk maps could help public health authorities decide where to perform scorpion envenomation surveillance and take preventive measures.

\section{Authors' Contributions}

Data were collected and interpreted by MAE, OT, and $\mathrm{AB}$ using MaxEnt and ArcGIS. The manuscript was prepared jointly by MAE and MAL. AB participated in the review process and incorporated valuable suggestions for improvement of the manuscript. All authors read and approved the final manuscript.

\section{Acknowledgments}

The authors are grateful to Tariq Zenjali for linguistic consultation. This project was funded by the Laboratory of Ecology and Environment (L2E) and CNERS06 Unit.

\section{Competing Interests}

The authors declare that they have no competing interests.

\section{References}

1. Abbas, N., Gaudioso-Tyzra, C., Bonnet, C., Gabriac, M., Amsalem, M., Lonigro, A., Padilla, F., Crest, M., MartinEauclaire, M.F. and Delmas, P. (2013) The scorpion toxin Amm VIII induces pain hypersensitivity through gain-of-function of TTX-sensitive $\mathrm{Na}+$ channels. Pain., 154: 1204-1215.

2. Lourenço, W.R. (2009) Reanalysis of the genus Scorpio linnaeus 1758 in sub-Saharan Africa and description of one new species from Cameroon (Scorpiones, Scorpionidae). Entomol. Mitt. Zool. Mus. Hamb., 15: 99-113.

3. Touloun, O., Slimani, T. and Boumezzough A. (2001) Epidemiological survey of scorpion envenomation in Southwestern Morocco. J. Venom. Anim. Toxins Incl. Trop. Dis., 7: 199-218.

4. El Hidan M.A., Touloun, O. and Boumezzough, A. (2015a) An epidemiological study of scorpion envenomation in the Zagora oases (Morocco). J Costal Life Med., 3: 704-7.

5. Chippaux, J.P. (2012) Emerging options for the management of scorpion stings. Drug. Des. Dev. Ther., 6:165-173. 
6. Yañez-Arenas, C., Peterson, A.T., Mokondoko, P., Rojas-Soto, O. and Martínez-Meyer, E. (2014) The use of ecological niche modeling to infer potential risk areas of snakebite in the Mexican state of Veracruz. PLoS One, 9: e100957.

7. Nori, J., Carrasco, P.A. and Leynaud, G.C. (2014) Venomous snakes and climate change: Ophidism as a dynamic problem. Clim. Chang., 122: 67-80.

8. Saupe, E.E., Papes, M., Selden, P.A. and Vetter, R.S. (2011) Tracking a medically important spider: Climate change, ecological niche modeling, and the brown recluse (Loxosceles reclusa). PLoS One, 6: e17731.

9. Wisz, M.S., Hijmans, R.J., Li, J., Peterson, A.T., Graham, C.H. and Guisan, A. (2008) NCEAS predicting species distributions working group. Effects of sample size on the performance of species distribution models. Divers. Distrib., 14: 763-773.

10. Vachon, M. (1949) Etude sur les scorpions. Ibid, 27: 66-100.

11. Lourenço, W.R. and Geniez, P. (2005) A new scorpion species of the genus Buthus leach, 1815 (Scorpiones, Buthidae) from Morocco. Euscorpius, 19: 1-6.

12. Hijmans, R.J., Cameron, S.E., Parra, J.L., Jones, P.G. and Jarvis, A. (2005) Very high resolution interpolated climate surfaces for global land areas. Int. J. Climatol., 25: 1965-1978.

13. Pearson, R.G., Dawson, T.P., Berry, P.M. and Harrison, P.A. (2002) Species: A spatial evaluation of climate impact on the envelope of species. Ecol. Model., 154: 289-300.

14. Kumar, S., Neven, L.G., Zhu, H. and Zhang, R. (2015) Assessing the global risk of establishment of Cydia pomonella (Lepidoptera: Tortricidae) using CLIMEX and max ent niche models. Behav. Ecol., 108: 1708-1719.

15. Chalghaf, B., Chlif, S., Mayala, B., Ghawar, W., Bettaieb, J., Harrabi, M., Benie, G.B., Michael, E. and Ben, S.A. (2017) Ecological niche modeling for the prediction of the geographic distribution of Cutaneous leishmaniasis in Tunisia. Am. J. Trop. Med. Hyg., 94: 844-851.

16. Phillips, S.J., Anderson, R.P. and Schapire, R.E. (2006) Maximum entropy modeling of species geographic distributions. Ecol. Model., 190: 231-259.

17. Elith, J., Graham, C.H., Anderson, R.P., Dudík, M., Ferrier, S., Guisan, A., Hijmans, R.J., Huettmann, F., Leathwick, J.R., Lehmann, A., Li, J., Lohmann, L.G., Loiselle, B.A., Manion, G., Moritz, C., Nakamura, M., Nakazawa, Y., Over-Ton, J.M., Peterson, A.T., Phillips, S.J., Richardson, K., Scachetti-Pereira, R., Schapire, R.E., Soberón, J., Williams S., Wisz, M.S. and Zimmermann, N.E. (2006) Novel methods improve prediction of species' distributions from occurrence data. Ecography, 29: 129-151.

18. Sor, R., Young-Seuk, P., Boets, P., Goethals, P.L.M. and Lek, S. (2017) Effects of species prevalence on the performance of predictive models. Ecol. Mod., 354: 11-19.

19. Nogués-Bravo, D. (2009) Predicting the past distribution of species climatic niches. Glob. Ecol. Biogeogr., 18: 521-531.

20. Fielding, A.H. and Bell, J.F. (1997) A review of methods for the assessment of prediction errors in conservation presence/absence models. Environ. Conserv., 24: 38-49.

21. Center for International Earth Science Information Network - CIESIN - Columbia University. (2016) Gridded Population of the World, Version 4 (GPWv4): Population Count. Palisades, NY: NASA Socioeconomic Data and Applications Center (SEDAC). Available from: http://sedac. ciesin.columbia.edu/downloads/docs/gpw-v4/gpw-v4-documentation.pdf. Accessed on 05.07.2017.

22. Peterson, A.T., Sanchez-Cordero, V., Beard, C.B. and Ramsey, J.M. (2002) Ecologic niche modeling and potential reservoirs for chagas disease, Mexico. Emerg. Infect. Dis., 8: 662-667.

23. Yañez-Arenas, C., Townsend, P.A., Rodríguez-Medina, K. and Barve, N. (2016) Mapping current and future potential snakebite risk in the new world. Clim. Chang., 134: 697-711.

24. Prendini, L. (2005) Scorpion diversity and distribution in southern Africa: Pattern and process. In: Huber, B.A., Sinclair, B.J., Lampe, K.H., editors. African Biodiversity: Molecules, Organisms, Ecosystems. Proceedings of the $5^{\text {th }}$ International Symposium on Tropical Biology, Museum Alexander Koenig. Springer Verlag, New York. p25-68.

25. Warburg, M.R., Goldenberg, S. and Ben-Horin, A. (1980) Scorpion species diversity and distribution within the Mediterranean and arid regions of northern Israel. J. Arid Environ., 3: 205-213.

26. Koch, L.E. (1981) The scorpions of Australia: Aspects of their ecology and zoogeography. In: Keast, A., editor. Ecological Biogeography of Australia. Junk, The Hague. p875-884.

27. Husemann, M., Schmitt, T., Stathi, I. and Habel J.C. (2012) Evolution and radiation in the scorpion Buthus elmoutaouakili lourenço and Qi 2006 (Scorpiones: Buthidae) at the foothills of the Atlas Mountains (North Africa). J. Hered., 103: 221-229.

28. El Hidan, M.A., Touloun, O., El Hiba, O. and Boumezzough, A. (2015b) Pathophysiological and neurobehavioral injuries in mice experimentally envenomed with androctonus liouvillei (Pallary, 1928) scorpion venom. Exp. Toxicol. Pathol., 68: 133-141.

29. Aboumaâd, B., Tiger, A., Khattabi, A., Soulaymani, R., Lahssaini, M., Benhassain, S.M. and Iba, N. (2014) Cardiac involvement and its complications about three cases of severe scorpion envenomation. Toxicon, 78: 78-82.

30. El Hidan, M.A., Touloun, O., El Oufir, R. and Boumezzough, A. (2016) Epidemiological and spatial analysis of scorpion stings in two regions of Morocco: Marrakesh-tensift-Al haouz and souss-massa-draa. $J$. Coast. Life Med., 4: 299-304.

31. El Hidan, M.A., Touloun, O., El Hiba, O., Chait, A., Hafid, J.E. and Boumezzough, A. (2015c) Behavioral, histopathological and biochemical impairments observed in mice envenomed by the scorpion: Hottentotta gentili (Pallary, 1924). Toxicon, 103: 19-29. 